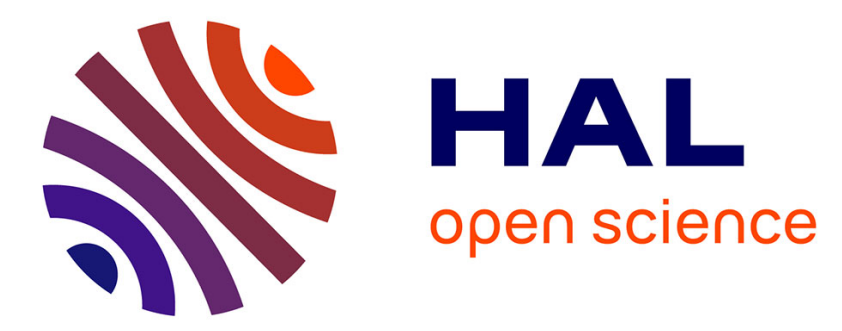

\title{
Determination of atmospheric soot carbon with a simple thermal method
}

\author{
Hélène Cachier, Marie-Pierre Bremond, Patrick Buat-Ménard
}

\section{To cite this version:}

Hélène Cachier, Marie-Pierre Bremond, Patrick Buat-Ménard. Determination of atmospheric soot carbon with a simple thermal method. Tellus B - Chemical and Physical Meteorology, 1989, 41B (3), pp.379-390. 10.1111/j.1600-0889.1989.tb00316.x . hal-03552767

\section{HAL Id: hal-03552767 https://hal.science/hal-03552767}

Submitted on 2 Feb 2022

HAL is a multi-disciplinary open access archive for the deposit and dissemination of scientific research documents, whether they are published or not. The documents may come from teaching and research institutions in France or abroad, or from public or private research centers.
L'archive ouverte pluridisciplinaire HAL, est destinée au dépôt et à la diffusion de documents scientifiques de niveau recherche, publiés ou non, émanant des établissements d'enseignement et de recherche français ou étrangers, des laboratoires publics ou privés. 


\title{
Determination of atmospheric soot carbon with a simple thermal method
}

\author{
By HÉLĖNE CACHIER, MARIE-PIERRE BREMOND and PATRICK BUAT-MÉNARD, \\ Centre des Faibles Radioactivités, Laboratoire mixte CNRS-CEA, Av de la Terrasse, \\ 91190 GIF sur Yvette, France
}

(Manuscript received 25 November 1987; in final form 11 August 1988)

\begin{abstract}
The dark component of carbonaceous aerosols is often referred to as "soot carbon". Soot consists of pure elemental carbon along with highly polymerized organic matter. An accurate discrimination between the soot carbon and the other components of carbonaceous aerosols is difficult to obtain by thermal analytical processes. Here, we report an optimization of a 2-step thermal method focused on the soot carbon determination of atmospheric particles. The organic material which does not absorb visible light is removed from the collection substrate under a pure oxygen flow during a precombustion step which has been carefully optimized in terms of temperature $\left(340^{\circ} \mathrm{C}\right)$ and duration $(2 \mathrm{~h})$. The remaining carbon content is determined by coulometric titration of the $\mathrm{CO}_{2}$ evolved from the combustion of the samples. The method has been tested quantitatively for analytical artefacts (e.g., "soot" production due to the charring of organics; soot losses during the preheating step) by using various standards such as pure graphite, pure organic and natural biogenic compounds and replicates of ambient air samples collected in urban, rural and forested areas in France. The results obtained so far indicate that this approach satisfactorily distinguishes between organic and soot carbon and allows reliable soot carbon determination at the $\mu \mathrm{g}$ level in atmospheric samples from a wide variety of environments. This study confirms that soot carbon is not composed primarily of elemental carbon. It appears to be a variable mixture of highly condensed organic compounds. These compounds may be either combustion-derived material or the result of low-temperature gas-to-particle conversion processes.
\end{abstract}

\section{Introduction}

One of the major sources for atmospheric carbonaceous particles derives from combustion processes (Wolff and Klimisch, 1982; Goldberg, 1985; Cachier et al., 1986). The dark component of these combustion-derived aerosols, often referred to as elemental or soot carbon, has remarkable physical and chemical properties. There is increasing evidence that soot carbon can affect our environment primarily: (a) through high optical absorption of solar radiation (Rosen et al., 1978), (b) through participation in heterogeneous reactions in the atmosphere or within cloud and rain droplets (Novakov, 1984;
Turco et al., 1983) and (c) as a scavenger for other atmospheric pollutants, especially highly carcinogenic PAH (Butler and Crossley, 1979). An important fraction of the mass of combustion aerosols is attached to submicron particles (Wolff et al., 1982) which enhances its role in atmospheric chemistry, primarily due to particle surface properties. Recently, studies have underlined that soot carbon can be transported far away from source regions, as far as in the remote marine or Arctic troposhere (Björseth et al., 1979; Andreae, 1983; Hansen and Rosen, 1984; Cachier et al., 1986).

The global atmospheric cycle of soot carbon has already been modelled (Turco et al., 1983), 
but the experimental data base is still limited. One of the reasons for this sparse data is the difficulty in assessing reliable soot concentration values for the ambient aerosol samples coming from different environments. The generating combustion processes suggest that soot carbon encompasses a complex mixture of highly polymerized organic matter along with pure elemental carbon (Goldberg, 1985) and the occurrence of the mixture is dependent on the sources which generate such particulate matter. Indeed, thermograms of various source and ambient particles (Dod et al., 1978; Gundel et al., 1984), explicitly show variations in the position and the width of the soot peak. Thus, any real differentiation between organic matter and soot is, to a large extent, arbitrary (Tanner et al., 1982). To date, several techniques have been developed to determine the soot component of carbonaceous aerosol samples. They include optical and thermal methods but limitations still remain, primarily due to the variable interferences between the different carbonaceous and/or mineral components (Wolff and Klimisch, 1982) and the difficulties in providing representative soot standards. The most severe drawback of thermal analysis of carbonaceous aerosols is the pyrolitic conversion of organic to soot carbon (charring). To address this important question, thermooptical methods are probably the most elegant procedures, since they consider the evolution of the optical properties of the sample during its heating (Dod et al., 1978; Huntzicker et al., 1982). However, the accuracy of optical measurements is very sensitive to the properties of the load deposited on the collection surface, i.e. the thickness of the deposit, the physical heterogeneity in size and morphology of the aerosol particles (Cadle and Groblicki, 1982; Gundel et al., 1984).

We present here a simpler and versatile variant of the thermal method based on a two-step combustion procedure. This method aims an optimized separation between soot and organic carbon. In this context, the experimental protocol focuses mainly on the consideration of the duration of the precombustion. It is shown that this approach allows one to minimize and to evaluate the major artefacts of the thermal procedure, i.e., the charring of the organics and the loss of the soot carbon during the volatilization step. The method can be applied to determine ambient soot carbon concentrations in a wide variety of samples.

\section{Experimental}

\subsection{Samples and standards}

Air filtration was performed at the CNRS campus, Gif sur Yvette, a semi-rural area, at different seasons and during field experiments conducted in the Landes pine forest, in Corsica coastal area (France) and in tropical regions in Africa. The aerosol samples were collected on precleaned glass fiber filters $(4,7 \mathrm{~cm}$ or $7 \mathrm{~cm}$ diameter Whatman GF/F, or $21 \times 24 \mathrm{~cm}$ Gelman $\mathrm{A} / \mathrm{E}), 5 \mathrm{~m}$ above the ground level, by either low volume $\left(3-12 \mathrm{~m}^{3} \mathrm{~h}^{-1}\right)$ or high volume filtration $\left(100 \mathrm{~m}^{3} \mathrm{~h}^{-1}\right)$. Sampling duration was adapted in order to obtain a carbon concentration in the range $10-80 \mu \mathrm{g} \mathrm{cm}^{-2}$ on the collection surface.

The optimization of the method required the analysis of other samples:

(a) standards which were prepared by dissolution of pure organic compounds in ethanol or acetone; glass fiber filters were then impregnated with known volumes of the solutions and airdried;

(b) plant samples which were washed with deionized water, dried and powdered; they were size-fractionated through different mesh-sieves and weighed aliquots of the calibrated powder were placed directly in the combustion boats;

(c) graphite samples which were obtained by filtration of either $<20 \mu \mathrm{m}$ commercial artificial graphite powder (Carbone-Lorraine, France) of black carbon obtained from the combustion of toluene in the laboratory.

\subsection{Analytical}

Decarbonatation of the aerosol samples was systematically performed through exposure of the filters to $\mathrm{HCl}$ fumes. The remaining carbon is referred to as atmospheric particulate carbon and is composed of primary and secondary organic carbon and of soot carbon (Cachier, 1987).

Samples were analysed using a two-step thermal procedure. During the first step, called the precombustion step, the samples are heated at low temperature, around $300^{\circ} \mathrm{C}$. The appropriate conditions of this precombustion, i.e., gas flow, temperature and duration are discussed later in 
this paper. They were chosen to minimize any "cross-over" effect between organics and soot. For optimizing this step, the temperature was found to be very critical and was carefully regulated in a $1{ }^{\circ} \mathrm{C}$ range in a $2-\mathrm{cm}$ diameter insulatedtubar furnace, by the means of a PID type power supply. For the second step, the combustion boat was placed in the furnace of a carbon analyser (Ströhlein Coulomat 702C) and the remaining thermally refractory carbon (soot carbon) was completely oxidized at $1100^{\circ} \mathrm{C}$. At this point, the $\mathrm{CO}_{2}$ which evolved was detected by coulometric titration. This system allows the determination of absolute carbon concentration values in the range of 5-5000 $\mu \mathrm{g}$ of carbon and its efficiency has been checked with various matrices such as pure graphite or mineral standards. It does not require any calibration, and thus offers the advantage over optical methods to avoid the problem of soot standards.

The determination of the total atmospheric cuibon content was obtained by direct oxidation of the sample in the carbon analyser and, consequently, leads to the assessment of the organic carbon load by comparison with the amount of soot carbon.

Filters were always pretreated by multi-solvent extraction (Cachier et al., 1986). The total carbon load of blank filters was found to be $1.0 \pm 0.5 \mu \mathrm{g}$ $\mathrm{cm}^{-2}$ and did not show any evolution when stored wrapped in aluminium foils during several months. The blank value was reduced by half if the filter had undergone the precombustion step; this value has been considered as the "soot carbon blank" value and could be attributed to the charring of high molecular weight organics which escaped the solvent extraction.

The accuracy of the analyser $(C<1 \mu \mathrm{gC})$ and the reproducibility of the load of blank filter samples allowed the determination of carbon contents down to $10 \mu \mathrm{gC}$ per sample. Thus, it has been possible to work on multiple aliquots of the same sample (average area: $3 \mathrm{~cm}^{2}$ ) and to test the reproducibility of the method. In all cases, the precision was better than $5 \%$. No systematic differences for the precision were found between samples analysed for total or for soot carbon contents. Consequently, the error can be primarily attributed to the aliquoting system, either due to uncertainties in the evaluation of the areas, or to the heterogeneity of the collection surfaces.

\section{Results and discussion}

Setting up the method has primarily necessitated the validation of the first step of the thermal treatment (called precombustion) during which the major part of the organic matter is removed from the sample. The precombustion conditions have to offer the best compromise between charring of the organic compounds which produces material determined as soot carbon, and the untimely partial removal of soot carbon. The optimal conditions have been set after several experiments which are described below.

\subsection{Carrier gas and sample heating rate}

Pure oxygen was chosen in order to minimize charring of the organic compounds. Indeed, this effect has been found to be more pronounced in non-oxidizing media such as helium or nitrogen (Cadle and Groblicki, 1982; Tanner et al., 1982). Also, the samples were heated rapidly at the determined precombustion temperature to favour the desorption of organics relative to chemical reactions leading to polycondensation and charring (Cadle et al., 1980; Tanner et al., 1982). Consequently, the samples were directly inserted into the heating zone of the furnace and were checked to reach the temperature within 2 minutes.

\subsection{Sample heating temperature and duration}

In order to estimate the soot content of aerosol particles, we have undertaken various investigations on the behaviour of the different components during the precombustion step. For this purpose, several fractions of a given aerosol sample were submitted to different precombustion scenarios where temperature and duration conditions were allowed to vary. At the end of each experiment, the remaining refractory carbon content was assessed. Earlier works on thermal analysis have shown that a clear separation between the different aerosol components is difficult to obtain thermally. However these studies, although conducted in various experimental conditions, have given evidence that the optimal temperature was in the range $300-350^{\circ} \mathrm{C}$ (Dod et al., 1978; Ellis et al., 1984; Ohta and Okita, 1984). But, to our knowledge, no 
indication of the duration of the precombustion was given in the literature.

It was observed visually that collection surfaces gradually lose their colour during the precombustion step. Long thermal treatments $(>24 \mathrm{~h})$ have shown that the dark-grey component of the aerosol could almost entirely undergo oxidation and therefore disappear at temperatures as low as $320^{\circ} \mathrm{C}$. Thus, it is clear that the soot carbon, if defined as the dark absorptive fraction of the aerosol, does volatilize from the filter during the precombustion step, probably through an oxidation process. In contrast, artificial samples obtained with pure graphite particles less than $20 \mu \mathrm{m}$ in diameter (graphite from Carbone-Lorraine, France) which were deposited on a filter did not show any alteration at temperature less than $340^{\circ} \mathrm{C}$. Although the size spectra of artificial and ambient samples are different, this result gives qualitative indication that ambient atmospheric soot carbon is not primarily composed of pure elemental carbon. A similar conclusion was obtained by other authors (Chang et al., 1982; Tanner et al., 1982; Goldberg, 1985; Castillo, 1986) and this will be discussed elsewhere.

Fig. 1 represents the typical evolution of the remaining carbon content of ambient aerosol
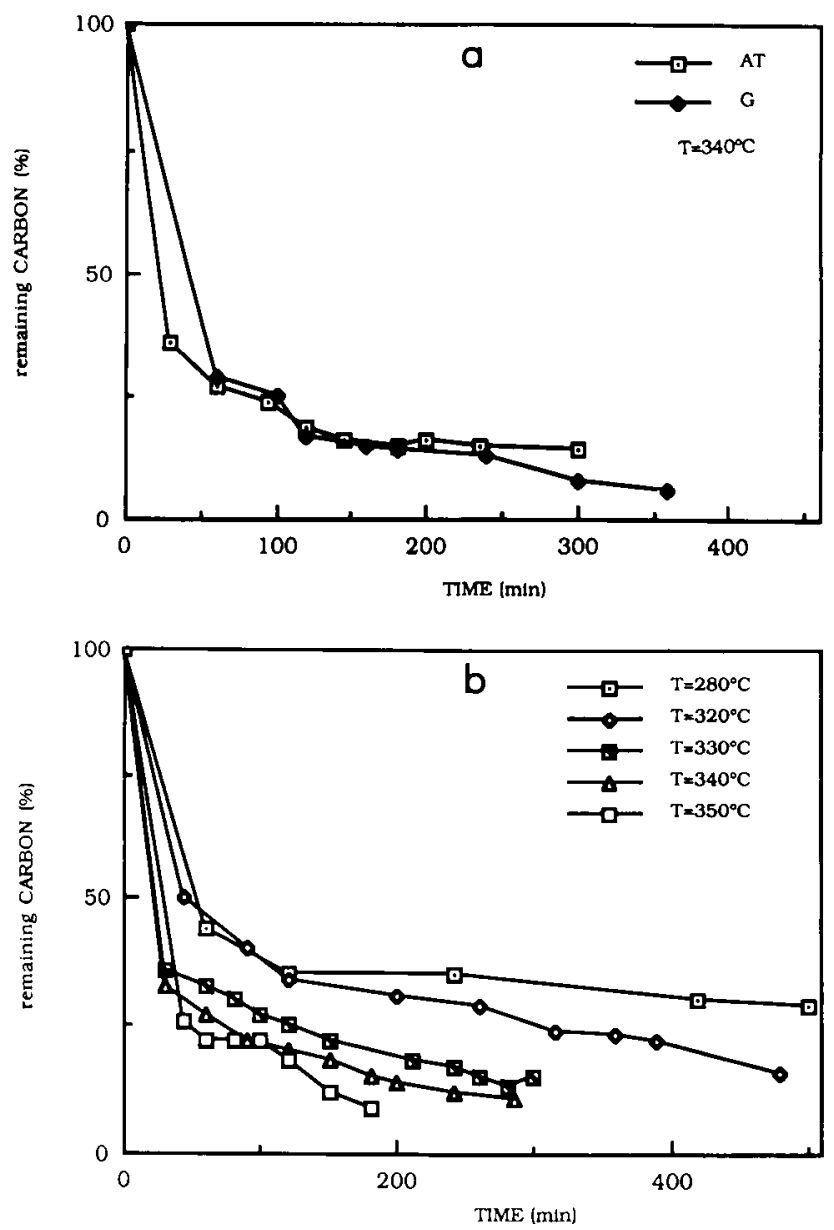

Fig. 1. Evolution pattern of the carbon content of ambient aerosol samples during the precombustion treatment. (a) Back-up filters from cascade impactor samples: urban sample (G, Gif, Oct/85) and rural sample (AT, Landes forest, Aug/84). (b) bulk filter samples from Gif at different temperatures. 
samples after precombustions of variable durations. Experiments were conducted in a large temperature range (from $260^{\circ} \mathrm{C}$ to $350^{\circ} \mathrm{C}$ ). In any case, all precombusted samples display the same pattern whatever the sampling location (Fig. la) or the chosen temperature for the precombustion process (Fig. 1b):

(a) The sample rapidly loses the major part of its carbon content $(\sim 1 \% / \mathrm{mn})$ during the first minutes of the precombustion. The more elevated the temperature, the faster this phenomenon takes place. This fast decrease can be attributed to the vaporization and/or the oxidation of volatile organic compounds. No noticeable change of the filter colour was observed along with this drastic change of the carbon content for short heating intervals.

(b) Later in the experiments, when the precombustion lasts longer than one hour, the loss of carbon is considerably less significant. This loss has to be related to the slow evolution of another carbonaceous component from the collection substrate. The simultaneous slow disappearance of the grey colour of the samples gives evidence that this fraction of the carbonaceous aerosols is their dark component, and thus probably includes soot carbon and the organic matter which would have charred during the precombustion treatment. Such a slow decomposition is most likely hidden by the evolution of the more volatile species during the first minutes of the thermal treatment. Our results indicate that within a precombustion duration range of $120-150 \mathrm{mn}$ the decomposition rate of this remaining refractory component is quasi-constant. It has been estimated for different samples and has been found to vary with the precombustion temperature. The values are reported in Table 1 .

Table 1. Decomposition rate of the refractory component of carbonaceous aerosols during the precombustion step

\begin{tabular}{lllc}
\hline $\begin{array}{l}\text { Precombustion } \\
\text { temperature }\left({ }^{\circ} \mathrm{C}\right)\end{array}$ & $\begin{array}{l}\text { No. } \\
\text { samples }\end{array}$ & $\begin{array}{l}K \pm \sigma \\
\left(\% \mathrm{~min}^{-1}\right)\end{array}$ & $\begin{array}{l}\text { Lost C\% during a 120 min } \\
\text { precombustion (calculated) }\end{array}$ \\
\hline 260 & 1 & 0.03 & 3.6 \\
280 & 1 & 0.05 & 6.0 \\
300 & 1 & 0.12 & 14.4 \\
320 & 5 & $0.14 \pm 0.03$ & 16.8 \\
330 & 2 & $0.17 \pm 0.02$ & 20.4 \\
340 & 8 & $0.20 \pm 0.04$ & 24.0 \\
350 & 2 & $0.37 \pm 0.04$ & 44.4 \\
\hline
\end{tabular}

$K$ is the percentage of lost refractory carbon per minute referred to total refractory carbon (soot carbon and pyrolysed organic matter)

Detailed results at $340^{\circ} \mathrm{C}$

\begin{tabular}{|c|c|c|c|c|}
\hline & Location & Date & $\begin{array}{l}C_{\text {soot }} \\
\left(\mu \mathrm{g} \mathrm{cm}^{-2}\right)\end{array}$ & $\begin{array}{l}K \\
\left(\% \min ^{-1}\right)\end{array}$ \\
\hline \multirow[t]{4}{*}{ Bulk sample } & Gif sur Yvette & Summer 84 & 25.0 & 0.20 \\
\hline & Gif sur Yvette & Fall 85 & 20.0 & 0.23 \\
\hline & $\begin{array}{l}\text { Gif sur Yvette } \\
\text { (near vegetation fire) }\end{array}$ & Winter 86 & 15.0 & 0.21 \\
\hline & Corsica & Fall 87 & 3.5 & 0.16 \\
\hline \multirow{5}{*}{$\begin{array}{l}\text { Back up flter } \\
\text { submicron particles }\end{array}$} & & & & \\
\hline & Gif sur Yvette & Fall 85 & 10.0 & 0.22 \\
\hline & Corsica & Fall 87 & 3.5 & 0.20 \\
\hline & $\begin{array}{l}\text { Khorogo } \\
\text { (Ivory Coast) }\end{array}$ & Summer 81 & 7.0 & 0.15 \\
\hline & $\begin{array}{l}\text { Congo } \\
\quad \text { (forest) }\end{array}$ & June 83 & 2.5 & 0.22 \\
\hline
\end{tabular}

Tellus 41B (1989), 3 
There is evidence that beyond $340^{\circ} \mathrm{C}$ there is an acceleration of the decomposition process. Furthermore, it was also found that at a given temperature, the decomposition rate of the refractory component of different aerosol samples are quite similar (Table 1 for $T=340^{\circ} \mathrm{C}$ ). Within the accuracy of our measurements, the thermal behaviour of soot carbon does not seem to be affected by the variety of mixtures which account for soot; the relative importance of the pure elemental carbon component towards that of the polymerized organic matter or the possible physical and chemical variability of the ambient soot particles do not influence significantly the decomposition rate of soot. It can also be deduced that the organic matter which has pyrolysed during the preheating process behaves thermally like soot.

Also, in our experimental conditions, the constancy of the decomposition rate of soot is maintained for differently loaded filters (range 2 to $25 \mu \mathrm{gC}_{\text {soot }} \mathrm{cm}^{-2}$, see Table 1). This apparently disagrees with Lin and Friedlander's assessments (1988). Different experimental conditions could explain this apparent discrepancy since in their work: (1) acetylene soot is taken as a substitute for the aerosol matrix; (2) thicker glass fiber filters are used; (3) precombustion is performed at higher temperatures. However, it has to be noted that the $K$ values presented in our work are within the range of those which can be extrapolated for low temperatures in Lin and Friedlander's work. (c) Following the organic compound volatilization and preceding the appearance of soot carbon decomposition, a few samples were found to exhibit a constant carbon content during precombustions of a duration up to $2 \mathrm{~h}$ (Fig. 2). One possible explanation is that this particular trend could be inferred to the charring of some refractory organics such as spores or pollens which temporarily hides the loss of soot carbon.

\subsection{Charring}

Previous works (Cadle et al., 1980, 1982; Huntzicker et al., 1982) have shown that, for average aerosol samples, up to $20 \%$ of organicto-soot carbon conversion could take place. Although experimental conditions were different in each method, the tested compounds displayed the same trends: pure organic compounds were found to be removed satisfactorily from the loaded filters with the exception of sugars and above all, highly aromatic hydrocarbons which structure resembles that of elemental carbon. Carbonization is also a complication when natural products such as pollen or plant debris are present in the sample (see Cadle et al., 1980; and Fig. 2).

In order to gain some insight into the phenomenon of charring induced by our thermal treatment, various experiments were performed by using samples in which the carbonaceous material was soot-free. Charring appeared to take place readily during the first minutes of the precombustion (Fig. 3). It could also be seen that

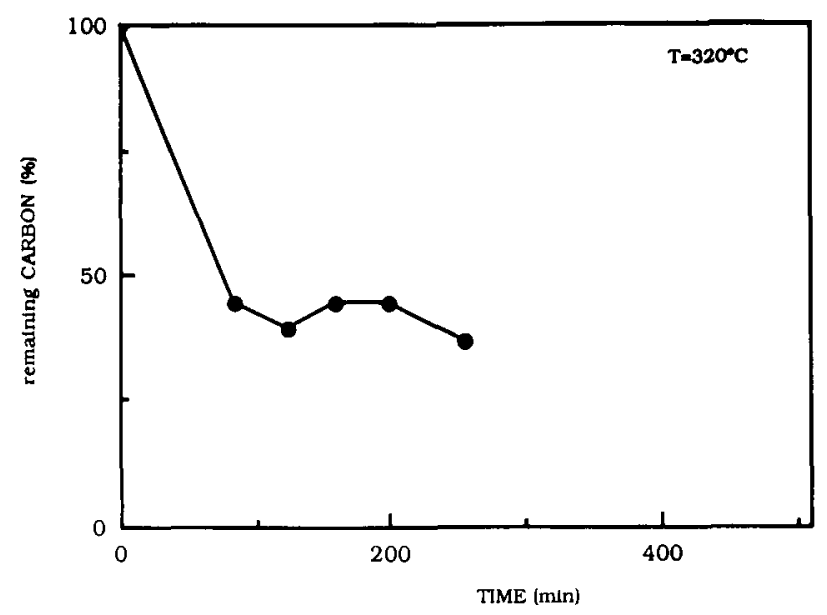

Fig. 2. Precombustion of a bulk aerosol sample collected during a pollen bloom (Gif, May/86). 


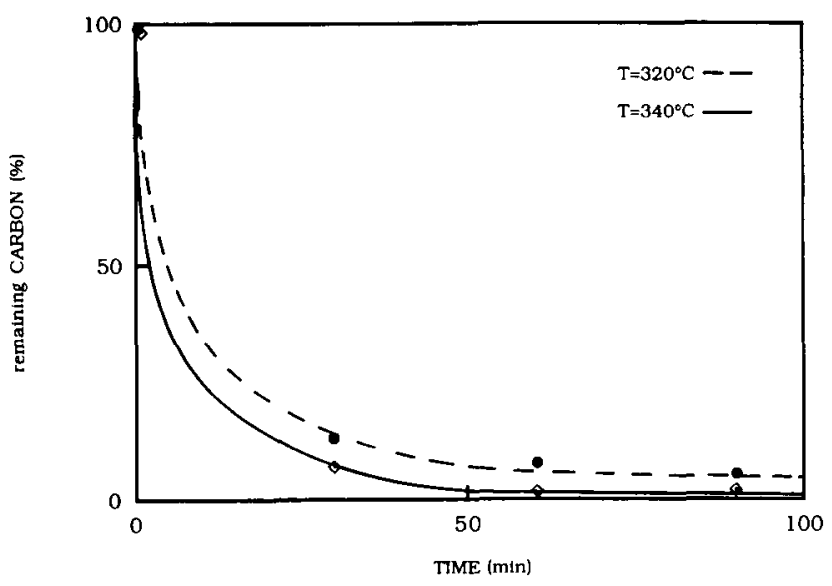

Fig. 3. Remaining carbon content of a preheated glucose sample.

changes in the temperature affect significantly the percentage of charred carbon which remains on the filter. The $\%$ of charring at $340^{\circ} \mathrm{C}$ for representative tested materials has been evaluated and is reported in Table 2. For refractory natural compounds (i.e., plant debris or pollens), the effectiveness of the method is very dependent upon particle size which has been found to be the most important parameter. According to Table 2, for particles smaller than $20 \mu \mathrm{m}$ (which is the case for average aerosols), pyrolysis during the precombustion would affect $10 \%$ or less of the initial organic matter content. Among the set of tested materials, only pure humic acids char significantly more than $30 \%$. These organic compounds are highly polymerized and hence undergo only very slow oxidation; consequently, their thermal behaviour compare with that of soot carbon. Although this could be a complication in the determination of ambient soot carbon contents, their contribution to the dark to black colour of carbonaceous aerosols has still to be assessed. This important question will be addressed elsewhere.

The results obtained here indicate that charring rates are systematically lower than what has been previously reported using other thermal procedures. Considering the average \% of charring found for aerosol particles in these earlier works ( $\sim 20 \%$ of the initial organic carbon) it may be assumed that in most of the aerosol samples, this percentage would be of the order of $10 \%$ or less by using our method.

\subsection{Optimized precombustion conditions}

During the precombustion treatment, apart from the removal of the organic matter, samples undergo two counteracting phenomena which can influence the yield of soot carbon analysis: charring of high molecular weight organics and early removal of the soot carbon. Their relative importance depends on both the temperature $(T)$ and the duration $(t)$ of the treatment (see sections 3.2 and 3.3 ).

The choice of the temperature is based on the following considerations. Charring varies with the chemical nature of the sample and displays a slow decrease with increasing temperature. In the $300-350^{\circ} \mathrm{C}$ temperature range, it can be assessed to affect commonly less than $20 \%$ of the total particulate organic carbon load. Within the same temperature range, soot carbon undergoes increasing oxidation with temperature; this process has been evaluated previously (Table 1) and, $340^{\circ} \mathrm{C}$ appears to be the highest acceptable temperature for an accurate determination of the loss of the soot component. Consequently, $340^{\circ} \mathrm{C}$ has been chosen as the optimized precombustion temperature.

The loss of soot carbon is minimized by a short precombustion step. However, the duration of the thermal treatment must be sufficient to allow the maximum release of the volatile organic matter. Glucose spiked filters have shown that the precombustion necessitates duration of $2 \mathrm{~h}$ at least to evolve the maximum organic content (Fig. 3). Furthermore at $340^{\circ} \mathrm{C}$, for our whole set 
Table 2. Charring tests: $T=340^{\circ} \mathrm{C} ; t=120 \mathrm{~min}$

Pure organic compounds

\begin{tabular}{lll}
\hline & $\begin{array}{l}\text { Total carbon on the filter } \\
\left(\mu \mathrm{g} \mathrm{cm}^{-2}\right)\end{array}$ & $\begin{array}{l}\text { Remaining carbon } \\
(\%)\end{array}$ \\
\hline glucose & 9 & 0 \\
& 15 & $6.9 \pm 0.6$ \\
pyrogallol & $20-40$ & $10.0 \pm 3.0$ \\
\hline
\end{tabular}

Thermally refractory natural mixtures (powders)

\begin{tabular}{|c|c|c|}
\hline & $\begin{array}{l}\text { Carbon \% in } \\
\text { the mixture }\end{array}$ & $\begin{array}{l}\text { Remaining carbon } \\
(\%)\end{array}$ \\
\hline $\begin{array}{l}\text { humic acids } \\
\text { (from marine sediment) }\end{array}$ & $55 \pm 5$ & $37 \pm 3$ \\
\hline $\begin{array}{l}\text { fulvic acids } \\
\text { (polysaccharides) } \\
\text { dry leaf }\end{array}$ & $49 \pm 3$ & $29 \pm 2$ \\
\hline$<160 \mu \mathrm{m}$ & $45+1$ & $26 \pm 1$ \\
\hline$<50 \mu \mathrm{m}$ & $45 \pm 1$ & $20 \pm 2$ \\
\hline $\begin{array}{l}<20 \mu \mathrm{m} \\
\text { green leaf }\end{array}$ & $45 \pm 1$ & $10 \pm 1$ \\
\hline $\begin{array}{l}\text { green leaf } \\
\quad<20 \mu \mathrm{m} \\
\text { marine sediment }\end{array}$ & $45 \pm 2$ & $15 \pm 1$ \\
\hline $\begin{array}{l}<20 \mu \mathrm{m} \\
\text { fluvial sediment }\end{array}$ & $3.2 \pm 0.2$ & $17 \pm 3$ \\
\hline $\begin{array}{l}<20 \mu \mathrm{m} \\
\text { soil (humus) }\end{array}$ & $4.3 \pm 0.1$ & $16 \pm 1$ \\
\hline$<20 \mu \mathrm{m}$ & $9.7 \pm 0.6$ & $11 \pm 1$ \\
\hline
\end{tabular}

of aerosol samples, this process appears to be achieved after $120 \mathrm{mn}$ at least, too. Consequently, this duration value has been adopted for the precombustion.

The above set of tested conditions for the determination of atmospheric soot by a two-step thermal procedure (precombustion under a pure oxygen flow, at $340^{\circ} \mathrm{C}$, and for $2 \mathrm{~h}$ ), appears to be more severe than that used by Ohta and Okita (1984). If the precombustion is controlled in the mentioned conditions, it is possible to evaluate the uncertainty of the method for the measurement of the soot carbon load of ambient aerosol samples.

Effectively, the rate of refractory carbon loss has been estimated to be:

$K^{\prime}=0.20 \times 120=24 \% \quad$ (Table 1$)$

and the pyrolysis rate of the organic matter $(Q)$ to be in the range $5-20 \%$.
If : $x=$ the initial soot carbon content of the aerosol sample, $1-x=$ its organic carbon content; then: $(1-x) Q$ represents the charring of the organic carbon; $x K^{\prime}+(1-x) Q K^{\prime}$ represents the loss of refractory carbon.

The method artefact can be defined as the difference between charring and loss:

$A=x K^{\prime}+(1-x) Q K^{\prime}-(1-x) Q$.

Fig. 4a represents $y=x-A$ as a function of $x$, for 3 possible values of the pyrolysis rate: 5,10 and $20 \%$. For the medium value $(10 \%)$, the charring and the loss of carbon balance each other $(y=x)$ when, in carbonaceous aerosols, the relative abundance of soot is $24 \%$ of the total carbon content. Assuming that the initial soot carbon content is equal to the load of refractory carbon which remains in the sample after the precombustion process, leads to an overestimate 

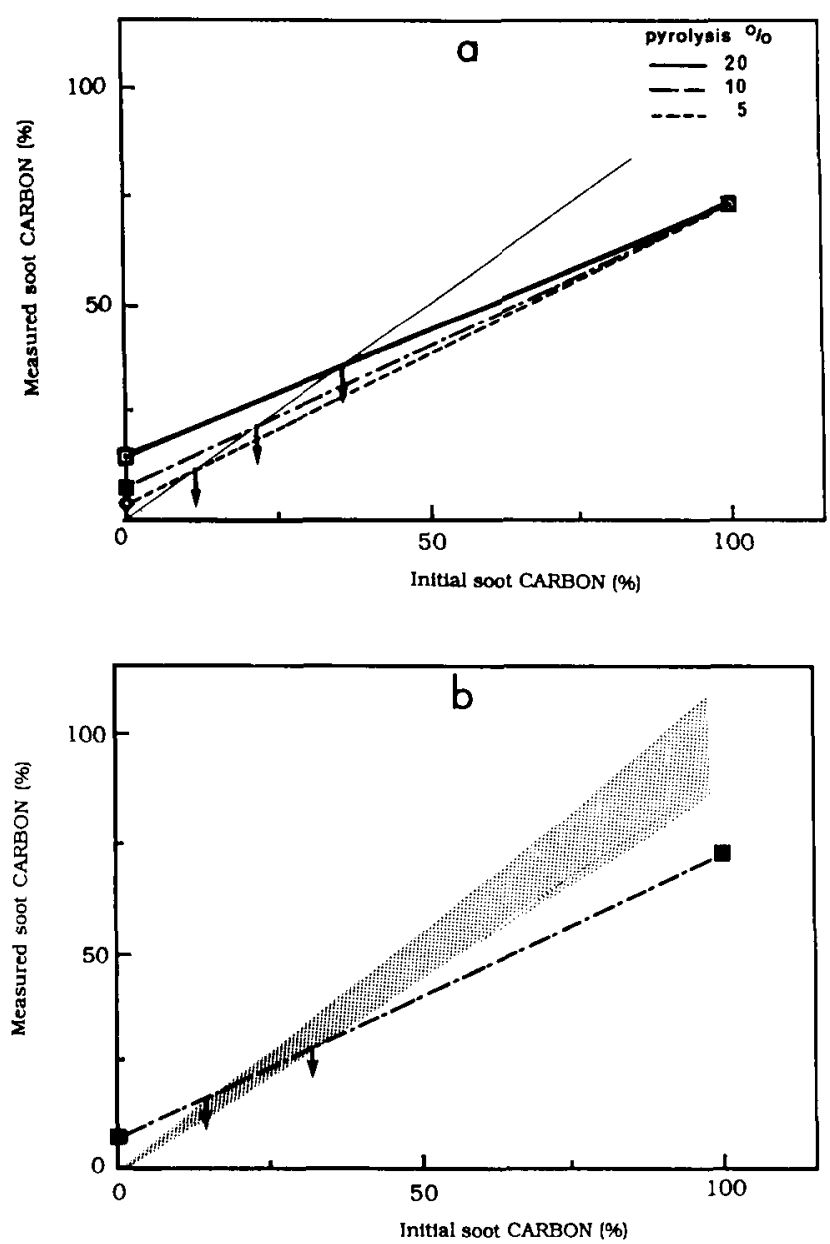

Fig. 4. Accuracy for atmospheric soot carbon determinations. (a) balance between the loss of "soot" carbon and the charring of organic matter for 5,10 and $20 \%$ pyrolysis rate. (b) limitations for initial soot concentration determination with a precision better than $10 \%(10 \%$ pyrolysis rate $)$.

if soot carbon is less abundant than $24 \%$. In contrast, if the initial soot carbon content is higher than this value, the method causes an underestimation of this content. It follows that if the relative accuracy of the determinations of the atmospheric soot carbon concentrations is less or equal to $10 \%$, no correction of the raw data has to be made for carbonaceous aerosols with soot carbon contents from 18 to $34 \%$ (Fig. 4b). According to previous works, this would be the range of the soot carbon content of most ambient aerosol samples from various environments
(Wolff and Klimisch, 1982; Goldberg, 1985; Sexton et al., 1985; Huntzicker et al., 1986; Japar et al., 1986). In very special situations when soot is either very abundant (Grosjean, 1984) or at a very low concentration level (Andreae et al., 1984; Clarke et al., 1984; Heintzenberg, 1985), soot carbon concentrations would have to be corrected. To our knowledge, the method presented here is the first attempt to consider such a type of correction with a thermal procedure (Cadle et al., 1980; Tanner et al., 1982; Wolff and Klimisch, 1982).

Tellus $41 \mathrm{~B}$ (1989), 3 
Table 3. Results for ambient aerosol (raw data): bulk samples or $\left(^{*}\right)$ back up filter of cascade impactor samples

\begin{tabular}{|c|c|c|c|c|c|}
\hline Location & Date & $\begin{array}{l}\text { Volume } \\
\left(\mathrm{m}^{3}\right)\end{array}$ & $\begin{array}{l}\mathrm{C}_{\text {total }} \\
\left(\mu \mathrm{g} \mathrm{m}^{-3}\right)\end{array}$ & $\begin{array}{l}\mathrm{C}_{\text {soot }} \\
\left(\mu \mathrm{g} \mathrm{m}^{-3}\right)\end{array}$ & $\begin{array}{l}\mathrm{C}_{\text {soot }} / \mathrm{C}_{\text {total }} \\
(\%)\end{array}$ \\
\hline \multicolumn{6}{|l|}{$\begin{array}{c}\text { Temperate } \\
\text { urban }\end{array}$} \\
\hline \multirow[t]{2}{*}{ Paris } & fall 84 & 67 & 5.8 & 1.6 & 28 \\
\hline & winter 85 & 3 & 20.5 & 5.9 & 29 \\
\hline \multirow[t]{17}{*}{ Gif/Yvette } & winter 86 & 74 & 3.4 & 1.0 & 30 \\
\hline & & 84 & 19.0 & 5.4 & 28 \\
\hline & & 329 & 4.8 & 0.9 & 19 \\
\hline & spring 86-87 & 130 & 7.7 & 1.5 & 19 \\
\hline & & 276 & 6.3 & 1.4 & 23 \\
\hline & & 585 & 3.7 & 0.9 & 24 \\
\hline & & 79 & 20.2 & 4.6 & 23 \\
\hline & & 109 & 4.0 & 1.0 & 24 \\
\hline & summer 84 & 1924 & 9.5 & 2.3 & 24 \\
\hline & fall $85-87$ & 973 & 13.3 & 2.5 & 19 \\
\hline & & 189 & 4.6 & 1.1 & 23 \\
\hline & & 104 & 4.9 & 1.0 & 21 \\
\hline & fall $85\left(^{*}\right)$ & 1973 & 12.0 & 2.0 & 17 \\
\hline & near fire & 28 & 75.9 & 10.3 & 14 \\
\hline & & 97 & 29.7 & 4.8 & 16 \\
\hline & & 60 & 18.1 & 4.1 & 23 \\
\hline & & 357 & 7.4 & 1.3 & 18 \\
\hline \multicolumn{6}{|l|}{ rural } \\
\hline $\begin{array}{l}\text { Landes forest } \\
\text { coastal }\end{array}$ & fall 84 & 3970 & 1.8 & 0.3 & 16 \\
\hline \multirow[t]{13}{*}{ Corsica } & spring 86 & 60 & 3.6 & 0.8 & 22 \\
\hline & & 90 & 1.3 & 0.4 & 33 \\
\hline & & 88 & 1.0 & 0.2 & 16 \\
\hline & & 87 & 1.5 & 0.2 & 13 \\
\hline & & 88 & 1.9 & 0.3 & 16 \\
\hline & & 44 & 2.2 & 0.6 & 26 \\
\hline & & 81 & 2.5 & 0.6 & 23 \\
\hline & & 83 & 2.3 & 0.5 & 21 \\
\hline & & 83 & 2.2 & 0.3 & 16 \\
\hline & & 84 & 1.6 & 0.1 & 7 \\
\hline & & 165 & 1.1 & 0.3 & 26 \\
\hline & & 156 & 1.6 & 0.3 & 18 \\
\hline & fire event & 37 & 1.8 & 0.7 & 40 \\
\hline \multicolumn{6}{|l|}{$\begin{array}{l}\text { Tropical } \\
\quad \text { savannah }\end{array}$} \\
\hline \multirow[t]{4}{*}{ Ivory Coast } & winter $81-82\left(^{*}\right)$ & 2460 & 6.3 & 0.9 & 14 \\
\hline & & 1070 & 12.1 & 1.6 & 13 \\
\hline & & 1300 & 20.9 & 3.1 & 15 \\
\hline & fall $82\left(^{*}\right)$ & 1400 & 1.2 & 0.2 & 17 \\
\hline \multicolumn{6}{|l|}{ forest } \\
\hline \multirow[t]{4}{*}{ Congo } & spring 83 & 53 & 6.7 & 1.1 & 17 \\
\hline & spring $83-84\left(^{*}\right)$ & 760 & 5.4 & 1.2 & 21 \\
\hline & & 769 & 5.4 & 1.1 & 21 \\
\hline & & 1310 & 3.6 & 0.7 & 20 \\
\hline
\end{tabular}




\section{Concluding remarks}

The study presented here focuses on the problems associated with the thermal determination of atmospheric soot carbon. The simple method set up in this work is based on the optimized conditions found to avoid as much as possible both the 2 counteracting phenomena of charring of the organic matter and loss of the soot carbon. This method has the potential to allow reliable soot carbon determination in atmospheric samples from a wide variety of environments. It could also be used for heterogenous collection surfaces and hence could lead to the determination of soot in rain and snow samples.

Soot carbon concentrations obtained to date are given in Table 3. Samples were collected in various environments and in different conditions. They display a wide range of carbon load (from 1 to $40 \mu \mathrm{gC} \mathrm{m}^{-3}$ ). For these samples, whatever their origin, soot carbon is always present in detectable amounts. The $\%$ of soot varies between 7 to $40 \%$ showing that the major part of the atmospheric particulate carbon is in the organic mode. This is in agreement with most of the results obtained in polluted environments (Wolff and Klimisch, 1982; Goldberg, 1985).

These investigations on the thermal behaviour of the bulk carbonaceous component of the aerosol allow to gain some insight on the nature of "soot carbon". Indeed, the thermal evolution of soot carbon is different from that of pure elemental carbon and this gives indication that soot carbon is not primarily composed of pure elemental carbon but rather a mixture of highly condensed organic compounds. Organic matter which has pyrolysed during the volatilization process is likely to behave thermally as soot carbon. Finally, ambient samples from the equatorial forest show a significant soot content with no apparent contribution from combustion processes (Clairac et al., 1988). This suggests that low-temperature processes (e.g., gas-to-particle conversion of gaseous precursors) may produce a natural organic aerosol which has the properties of soot.

We stress that a clear discrimination between natural organics and combustion-derived products is very difficult to obtain either using their thermal or optical properties. Much further work is needed on the nature itself of soot carbon. In this respect, one important parameter could be the atomic ratio $\mathrm{H} / \mathrm{C}$ which provides indications on the condensation degree of the carbonaceous matter. The systematic measurement of this ratio is currently underway in our laboratory.

\section{Acknowledgement}

This work was supported by CNRS and CEA, Contribution no. 926.

\section{REFERENCES}

Andreae, M. O. 1983. Soot carbon and excess fine potassium: long-range transport of combustionderived aerosols. Science 220, 1148-1151.

Andreae, M. O., Andreae, T. W., Ferek, R. J. and Raemdonck, H. 1984. Long-range transport of soot carbon in the marine atmosphere. Sci. Total Environ. $36,73-80$.

Björseth, A., Lunde, G. and Lindskog, A. 1979. Longrange transport of polycyclic aromatic hydrocarbons. Atmos. Environ. 13, 45-53.

Butler, J. D. and Crossley, P. 1979. An appraisal of relative airborne sub-urban concentrations of polycyclic aromatic hydrocarbons monitored indoors and outdoors. Sci. Total Environ. 11, 53-58.

Cachier, H. 1987. Atmospheric particulate carbon cycle; evidence from isotopic measurements. Ph.D. Thesis (in French). Université Paris 7, 234 pp.

Cachier, H., Buat-Ménard, P., Fontugne, M. and Chesselet, R. 1986. Long-range transport of con- tinentally-derived particulate carbon in the marine atmosphere: evidence from stable carbon isotope studies. Tellus 38B, 161-177.

Cadle, S. H. and Groblicki, P. J. 1982. An evaluation of methods for the determination of organic and elemental carbon in particulate samples. In: Particulate carbon: atmospheric life cycle (eds. G. T. Wolff and R. L. Klimisch). New York: Plenum, 89-108.

Cadle, S. H., Groblicki, P. J. and Stroup, D. P. 1980. Automated carbon analyser for particulate samples. Anal. Chem. 52, 2201-2206.

Castillo, R. 1986. An analysis of black aerosol found in two winter atlantic coastal snow storms at Whiteface Mountain, New York. J. Aerosol Sci. 17, 677-684.

Chang, S. G., Brodzinsky, R., Gundel, L. A. and Novakov, T. 1982. Chemical and catalytic properties of elemental carbon. In: Particulate carbon: atmospheric life cycle (eds. G. T. Wolff and R. L. Klimisch). New York: Plenum, 159-181. 
Clairac, B., Delmas, R., Cros, B., Cachier, H., BuatMénard, P. and Servant, J. 1988. Formation and chemical composition of atmospheric aerosols in an equatorial forest area. J. Atmos. Chem. 6, 301-322.

Clarke, A. D., Weiss, R. E. and Charlson, R. J. 1984. Elemental carbon aerosols in the urban, rural, and remote-marine troposphere and in the stratosphere: inferences from light absortion data and consequences regarding radiative transfer. Sci. Total Environ. 36, 97-102.

Dod, R. L., Rosen, H. and Novakov, T. 1978. Opticothermal analysis of the carbonaceous fraction of aerosol particles. Lawrence Berkeley Laboratory annual report, Univ. of Calif., 2-10.

Ellis, E. C., Novakov, T. and Zeldin, M. D. 1984. Thermal characterization of organic aerosols. Sci. Total Environ. 36, 261-270.

Goldberg, E. D. 1985. Black carbon in the environment (properties and distribution). New York: Wiley, $198 \mathrm{pp}$.

Grosjean, D. 1984. Particulate carbon in Los Angeles air. Sci. Total Environ. 32, 133-145.

Gundel, L. A., Dod, R. L., Rosen, H. and Novakov, T. 1984. The relationship between optical attenuation and black carbon concentration for ambient and source particles. Sci. Total Environ. 36, 197-202.

Hansen, A. D. A. and Rosen, H. 1984. Vertical distribution of particulate carbon, sulfur, and bromine in the arctic haze and comparison with ground-level measurements at Barrow, Alaska. Geophys. Res. Lett. $11,381-384$.

Heintzenberg, J. 1985. What can we learn from aerosol measurements at baseline stations? J. Atm. Chem. 3, 153-169.

Huntzicker, J. J., Johnson, R. L., Shah, J. J. and Cary, R. A. 1982. Analysis of organic and elemental carbon in ambient aerosols by a thermal-optical method. In: Particulate carbon: atmospheric life cycle (eds. G. T. Wolff and R. L. Klimisch). New York: Plenum, 7985.

Huntzicker, J. J., Heyerdahl, E. K., McDow, S. R., Rau, J. A., Griest, W. H. and MacDougall C. S. 1986. Combustion as the principal source of carbon- aceous aerosol in the Ohio River Valley. JAPCA 36 , 705-709.

Japar, S. M., Brachaczek, W. W., Gorse, R. A., Norbeck, J. M. and Pierson, W. R. 1986. The contribution of elemental carbon to the optical properties of rural atmospheric aerosols. Atmos. Environ. 20, 1281-1289.

Lin, C. and Friedlander S. K. 1988. A note on the use of glass fiber filters in the thermal analysis of carbon containing aerosols. Atmos. Environ. 22, 605-607.

Novakov, T. 1984. The role of soot and primary oxidants in the atmospheric chemistry. Sci. Total Environ. 36, 1-10.

Ohta, S. and Okita, T. 1984. Measurements of particulate carbon in urban and marine air in japanese areas. Atmos. Environ. I8, 2439-2445.

Rosen, H., Hansen, A. D. A., Gundel, L. and Novakov, T. 1978. Identification of the optically absorbing component in urban aerosols. Appl. Opt. 17, 3859-3861.

Sexton, K., Liu, K. S., Hayward, S. B. and Spengler, J. D. 1985. Characterization and source apportionment of wintertime aerosol in a woodburning community. Atmos. Environ. 19, 1225-1236.

Tanner, R. L., Gaffney, J. S. and Phillips, M. F. 1982. Determination of organic and elemental carbon in atmospheric aerosol samples by thermal evolution. Anal. Chem. 54, 1627-1630.

Turco, R. P., Toon, O. B., Whitten, R. C., Pollack, J. B. and Hamill, P. 1982. The global cycle of particulate elemental carbon: a theoretical assessment. In: Precipitation, scavenging, dry deposition and resuspension, vol. 2. New York: Elsevier, 1337-1351.

Wolff, G. T. and Klimisch, R. L. 1982. Particulate carbon: atmospheric life cycle. New York: Plenum, $411 \mathrm{pp}$.

Wolff, G. T., Groblicki, P. J., Cadle, S. H. and Countess, R. J. 1982. Particulate carbon at various locations in the United States. In: Particulate carbon: atmospheric life cycle (eds. G. T. Wolff and R. L. Klimisch). New York: Plenum, 297-314. 